\title{
Decision Making of Banana Varieties Based on Land in Samarinda Using ELECTRE Method
}

\author{
Heliza Rahmania Hatta ${ }^{1}$, Ramaulvi Muhammad Akhyar ${ }^{2}$, Dyna Marisa Khairina ${ }^{3}$, Septya Maharani ${ }^{4}$, Haviluddin ${ }^{5}$, \\ Purnawansyah $^{6}$ \\ 1,2,3,4,5 Faculty of Computer Science and Information Technology, Mulawarman University, Indonesia \\ ${ }^{6}$ Faculty of Computer Science, Universitas Muslim Indonesia \\ heliza_rahmania@yahoo.com,ramaulvimuhammadakhyar@gmail.com,dyna.ilkom@gmail.com,septyamaharani@gmail.com, \\ haviluddin@gmail.com,purnawansyah@gmail.com
}

\begin{abstract}
Indonesia is an agrarian country, a country with fertile soil and rich in nutrients so that a lot of land that can be used as agricultural land for a variety of plants one of which is a banana plant. Banana is a plant that has a good adaptability to the condition of water shortage, so that many planted bananas in dry land in East Kalimantan. Despite having good adaptability but some varieties of bananas cannot grow on certain lands. Utilization of Decision Support Systems (DSS) as one of the computerized intelligent systems can be used to help make decisions quickly, accurately and consistently. The system was developed by applying the ELECTRE method where the criteria used were soil type, rainfall, soil fertility level, and soil $\mathrm{pH}$. Alternative bananas used there were 10 types of Ambon Banana, Kepok Banana, Mas Banana, Nangka Banana, Lampung Banana, Raja Banana, Tanduk Banana, Awak Banana, Merah Banana, and Barangan Banana. The system successfully selected banana varieties to the land in Samarinda, where the best variety of selected varieties was Raja Banana.
\end{abstract}

Keywords—bananas; DSS; ELECTRE; land; criteria

\section{INTRODUCTION}

Land is an area on the surface of the earth, covering all components of the biosphere that could be considered permanent or cyclical located above and below the region, including the atmosphere, soil, parent rock, relief, hydrology, plants and animals, as well as all activity of past and present human activity. All of which affect the use of land by humans today and in the future. Land have many kinds of lands including plantation land, mining land, and agricultural land $[1,2]$. The use of the land itself must be in accordance with the results to be obtained from the land use and the suitability of the land. Indonesia is a country with many clusters of islands surrounded by vast waters, of course, land use needs to be through the analysis of conformity in advance so that its use can be more optimum.

Indonesia is an agrarian country, a country with fertile soil and rich in nutrients so many land that can be used as agricultural land. Indonesia has many types of land that has earned an honor as a host and earth and soil research site in 1982 along with FAO [3]. Agricultural land in Indonesia is very diverse with the characteristics of the soil of each region scattered throughout the archipelago in Indonesia, so the variety of its use, especially for the activities of food crops also has a variety of variations. Many food crops that can grow in Indonesia in accordance with the land or land that is the rooting medium [4], one of which is a banana plant. In Indonesia Banana Plants are an important horticultural commodity that has a variety or type, there are many types of bananas in Indonesia, such as plantains, ambon banana, kepok banana, and others.

Banana is a plant that has a good adaptability to the condition of water shortage, so that many bananas planted farmers in dry land in East Kalimantan. Despite having good adaptability but some varieties of bananas cannot grow on certain lands [5]. Selection of banana varieties in accordance with the criteria of land can be assisted with decision support systems. Decision support systems can provide the best recommendations based on data from criteria and alternatives $[6,7]$. Decision support systems have several methods i.e., AHP [8], TOPSIS [9], K-Means [10] then one of which is the method of ELECTRE, which can provide recommendations as a consideration for decision-making appropriately.

\section{METHODOLOGY}

Decision support system of selection of banana varieties on land in Samarinda using this method of ELECTRE can be used by modern farmers or researchers who want to find alternative bananas in accordance with the criteria of land. The system of selection of banana varieties to the land using the ELECTRE method has eight stages of the process to get the recommendation of banana varieties, Fig. 1

\section{RESULT AND DISCUSSION}

The testing phase of the application of ELECTRE is required to evaluate alternative results provided by the system with manually done results in order to minimize errors in the system. For example user enter the weight as in Table I.

TABLE I. WEIGHT (W)

\begin{tabular}{|l|l|}
\hline Weights & Criteria Values \\
\hline Soil Type (W1) & Peat (1) \\
\hline Rainfall (W2) & Enough (4) \\
\hline Fertility Level (W3) & Medium (3) \\
\hline Soil pH (W4) & Neutral (2) \\
\hline
\end{tabular}




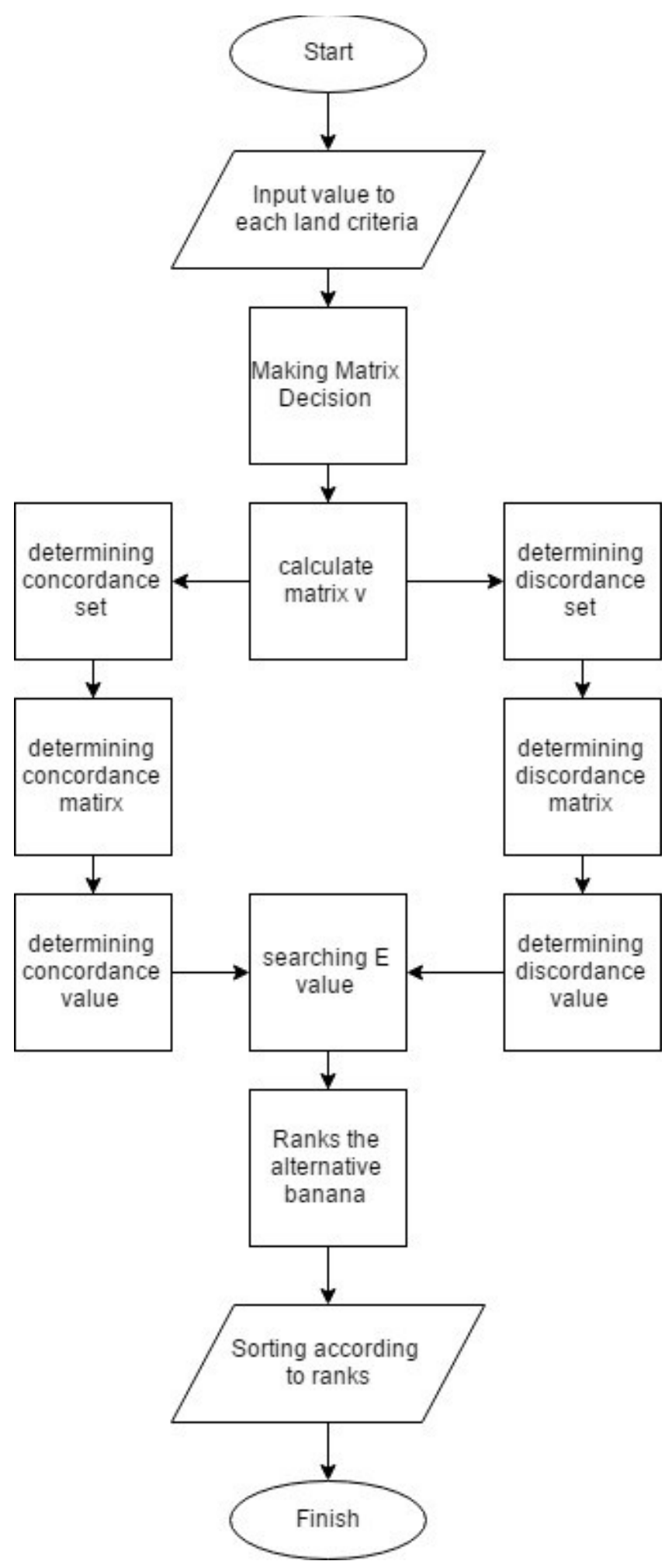

TABLE II. RESUlT OF NORMALIZATION OF DECISION MATRIX

\begin{tabular}{|l|l|l|l|l|l|}
\hline \multirow{2}{*}{ No } & \multirow{2}{*}{ Alternative } & \multicolumn{4}{|l|}{ Criteria } \\
\cline { 3 - 6 } & $\begin{array}{l}\text { Soil } \\
\text { Type }\end{array}$ & Rainfall & $\begin{array}{l}\text { Fertility } \\
\text { Level }\end{array}$ & Soil pH \\
\hline 1 & Ambon Banana & 0.472 & 0.286 & 0.286 & 0.248 \\
\hline 2 & Kepok Banana & 0.472 & 0.381 & 0.381 & 0.372 \\
\hline 3 & Mas Banana & 0.189 & 0.381 & 0.381 & 0.372 \\
\hline 4 & Lampung Banana & 0.189 & 0.286 & 0.286 & 0.372 \\
\hline 5 & Nangka Banana & 0.094 & 0.191 & 0.191 & 0.372 \\
\hline 6 & Raja Banana & 0.378 & 0.286 & 0.286 & 0.248 \\
\hline 7 & Awak Banana & 0.189 & 0.286 & 0.191 & 0.248 \\
\hline 8 & Tanduk Banana & 0.189 & 0.191 & 0.286 & 0.248 \\
\hline 9 & Merah Banana & 0.189 & 0.286 & 0.477 & 0.248 \\
\hline 10 & Barangan Banana & 0.472 & 0.477 & 0.286 & 0.372 \\
\hline
\end{tabular}

TABLE III. WEIGHTING ON A NORMALIZED MATRIX

\begin{tabular}{|c|c|c|c|c|c|}
\hline \multirow[b]{2}{*}{ No } & \multirow[b]{2}{*}{ Alternative } & \multicolumn{4}{|c|}{ Criteria } \\
\hline & & $\begin{array}{l}\text { Soil } \\
\text { Type }\end{array}$ & Rainfall & $\begin{array}{l}\text { Fertility } \\
\text { Level }\end{array}$ & Soil $\mathrm{pH}$ \\
\hline 1 & Ambon Banana & 0.472 & 1.144 & 0.858 & 0.496 \\
\hline 2 & Kepok Banana & 0.472 & 1.526 & 1.144 & 0.744 \\
\hline 3 & Mas Banana & 0.189 & 1.526 & 1.144 & 0.744 \\
\hline 4 & Lampung Banana & 0.189 & 1.144 & 0.858 & 0.744 \\
\hline 5 & Nangka Banana & 0.094 & 0.763 & 0.572 & 0.744 \\
\hline 6 & Raja Banana & 0.378 & 1.144 & 0.858 & 0.496 \\
\hline 7 & Awak Banana & 0.189 & 1.144 & 0.572 & 0.496 \\
\hline 8 & Tanduk Banana & 0.189 & 0.763 & 0.858 & 0.496 \\
\hline 9 & Merah Banana & 0.189 & 1.144 & 1.43 & 0.496 \\
\hline 10 & Barangan Banana & 0.472 & 1.907 & 0.858 & 0.744 \\
\hline
\end{tabular}

TABLE IV. CONCORDANCE MATRIX

\begin{tabular}{|l|l|l|l|l|l|l|l|l|l|l|}
\hline & 1 & 2 & 3 & 4 & 5 & 6 & 7 & 8 & 9 & 10 \\
\hline 1 & - & 1 & 1 & 8 & 8 & 10 & 10 & 10 & 7 & 4 \\
\hline 2 & 10 & - & 10 & 10 & 10 & 10 & 10 & 10 & 7 & 6 \\
\hline 3 & 9 & 9 & - & 10 & 10 & 9 & 10 & 10 & 7 & 5 \\
\hline 4 & 9 & 2 & 3 & - & 10 & 9 & 10 & 10 & 7 & 5 \\
\hline 5 & 2 & 2 & 2 & 2 & - & 2 & 5 & 6 & 2 & 2 \\
\hline 6 & 9 & 0 & 1 & 8 & 8 & - & 10 & 10 & 7 & 3 \\
\hline 7 & 6 & 0 & 1 & 5 & 8 & 6 & - & 7 & 7 & 0 \\
\hline 8 & 5 & 0 & 1 & 4 & 8 & 5 & 6 & - & 3 & 3 \\
\hline 9 & 9 & 3 & 4 & 8 & 8 & 9 & 10 & 10 & - & 3 \\
\hline 10 & 10 & 7 & 7 & 10 & 10 & 10 & 10 & 10 & 7 & - \\
\hline
\end{tabular}

So that from Table I we get the weight value $\mathrm{W}=(1,4,3$, 2 ) against a land in Samarinda as a trial. The next steps to be done based on Fig. 1.

1) Normalization of Decision Matrix. General matrix decision formula:

TABLE V. DISCORDANCE MATRIX

\begin{tabular}{|l|l|l|l|l|l|l|l|l|l|l|}
\hline & 1 & 2 & 3 & 4 & 5 & 6 & 7 & 8 & 9 & 10 \\
\hline 1 & - & 1 & 1 & 0.875 & 0.65 & 0 & 0 & 0 & 1 & 1 \\
\hline 2 & 0 & - & 0 & 0 & 0 & 0 & 0 & 0 & 0.75 & 1 \\
\hline 3 & 0.743 & 1 & - & 0 & 0 & 0.496 & 0 & 0 & 0.75 & 1 \\
\hline 4 & 1 & 1 & 1 & - & 0 & 0.762 & 0 & 0 & 1 & 1 \\
\hline 5 & 1 & 1 & 1 & 1 & - & 1 & 1 & 1 & 1 & 1 \\
\hline 6 & 1 & 1 & 1 & 1 & 0.65 & - & 0 & 0 & 1 & 1 \\
\hline 7 & 1 & 1 & 1 & 1 & 0.65 & 1 & - & 0.75 & 1 & 1 \\
\hline 8 & 1 & 1 & 1 & 1 & 0.867 & 1 & 1 & - & 1 & 1 \\
\hline 9 & 0.496 & 1 & 1 & 0.434 & 0.289 & 0.33 & 0 & 0 & - & 1 \\
\hline 10 & 0 & 0.75 & 0.75 & 0 & 0 & 0 & 0 & 0 & 0.75 & - \\
\hline
\end{tabular}


TABLE VI. CONCORDANCE DOMINANT MATRIX

\begin{tabular}{|l|l|l|l|l|l|l|l|l|l|l|}
\hline & 1 & 2 & 3 & 4 & 5 & 6 & 7 & 8 & 9 & 10 \\
\hline 1 & - & 0 & 0 & 1 & 1 & 1 & 1 & 1 & 1 & 0 \\
\hline 2 & 1 & - & 1 & 1 & 1 & 1 & 1 & 1 & 1 & 0 \\
\hline 3 & 1 & 1 & - & 1 & 1 & 1 & 1 & 1 & 1 & 0 \\
\hline 4 & 1 & 0 & 0 & - & 1 & 1 & 1 & 1 & 1 & 0 \\
\hline 5 & 0 & 0 & 0 & 0 & - & 0 & 0 & 0 & 0 & 0 \\
\hline 6 & 1 & 0 & 0 & 1 & 1 & - & 1 & 1 & 1 & 0 \\
\hline 7 & 0 & 0 & 0 & 0 & 1 & 0 & - & 1 & 1 & 0 \\
\hline 8 & 0 & 0 & 0 & 0 & 1 & 0 & 0 & - & 0 & 0 \\
\hline 9 & 1 & 0 & 0 & 1 & 1 & 1 & 1 & 1 & - & 0 \\
\hline 10 & 1 & 1 & 1 & 1 & 1 & 1 & 1 & 1 & 1 & - \\
\hline
\end{tabular}

TABLE VII. DISORDANCE DOMINANT MATRIX

\begin{tabular}{|l|l|l|l|l|l|l|l|l|l|l|}
\hline & 1 & 2 & 3 & 4 & 5 & 6 & 7 & 8 & 9 & 10 \\
\hline 1 & - & 1 & 1 & 1 & 1 & 0 & 0 & 0 & 1 & 1 \\
\hline 2 & 0 & - & 0 & 0 & 0 & 0 & 0 & 0 & 1 & 1 \\
\hline 3 & 1 & 1 & - & 0 & 0 & 0 & 0 & 0 & 1 & 1 \\
\hline 4 & 1 & 1 & 1 & - & 0 & 1 & 0 & 0 & 1 & 1 \\
\hline 5 & 1 & 1 & 1 & 1 & - & 1 & 1 & 1 & 1 & 1 \\
\hline 6 & 1 & 1 & 1 & 1 & 1 & - & 0 & 0 & 1 & 1 \\
\hline 7 & 1 & 1 & 1 & 1 & 1 & 1 & - & 1 & 1 & 1 \\
\hline 8 & 1 & 1 & 1 & 1 & 1 & 1 & 1 & - & 1 & 1 \\
\hline 9 & 0 & 1 & 1 & 0 & 0 & 0 & 0 & 0 & - & 1 \\
\hline 10 & 0 & 1 & 1 & 0 & 0 & 0 & 0 & 0 & 1 & - \\
\hline
\end{tabular}

$r_{i j}=\frac{x_{i j}}{\sqrt{\sum_{i=1}^{m} x_{i j}^{2}}}$ for $i=1,2,3, \ldots, m$ and $j=1,2,3, \ldots, n$.

The result of calculation based on Eq. 1 can be seen in Table II.

2) Weighting on a normalized matrix. The result of multiplying the preference of each criterion with a normalized decision matrix can be seen in Table III.

3) Determining the Set of Concordance and Discordance Index.

a) Concordance. A criteria in an alternative includes concordance if:

$$
\begin{gathered}
C_{k l=}=\left\{j, v_{k j} \geq v_{l j}\right\}, \text { for } j=1,2,3, \ldots, n . \\
C_{12}=\left\{j, v_{1 j} \geq v_{2 j}\right\}, \text { for } j=1,2,3, \ldots 1=\{1,2,3,4\} \\
C_{13}=\left\{j, v_{1 j} \geq v_{3 j}\right\}, \text { for } j=1,2,3=\{2,3,4\}
\end{gathered}
$$

And so on up to

$$
\begin{aligned}
C_{110} & =\left\{j, v_{15 j} \geq v_{14 j}\right\}, \text { for } j=1,2,3, \ldots 10 \\
& =\{1,2,3,4\}
\end{aligned}
$$

b) Discordance. A criteria in an alternative includes discordance if:

$$
\begin{gathered}
D_{k l}=\left\{j, v_{k j}<v_{l j}\right\}, \text { for } j=1,2,3, \ldots, n . \\
D_{12}=\left\{j, v_{1 j}<v_{2 j}\right\}, \text { for } j=1,2,3, \ldots 10=\{0\} \\
D_{13}=\left\{j, v_{1 j}<v_{3 j}\right\}, \text { for } j=1,2,3, \ldots 10=\{1\}
\end{gathered}
$$

And so on up to

$$
D_{110}=\left\{j, v_{15 j}<v_{14 j}\right\} \text {, for } j=1,2,3=\{0\}
$$

4) Calculating Concordance and Disorder Matrices. a) Calculate concordance matrix. So from Eq. 2 the obtained sconcordance matrix which can be seen in Table IV.

$$
C_{k l}=\sum_{j \in C_{k l}} w_{j}
$$

b) Calculate discordance matrix. For $j$ where $\max \left\{\left|v_{k j}-v_{l j}\right|\right\}_{\forall j}=0$, then the value $d_{k l}$ is considered equal to 0 . So from Eq. 3 the obtained disordance matrix as in Table V.

$$
d_{k l}=\frac{\max \left\{\left|v_{k j}-v_{l j}\right|\right\}_{j \in D_{k l}}}{\max \left\{\left|v_{k j}-v_{l j}\right|\right\}_{\forall j}}
$$

5) Determine the dominant matrix of concordance and discordance.

a) Calculates the dominant matrix of concordance. The threshold value $(\underline{c})$ is Eq. 4.

$$
\begin{gathered}
\underline{c}=\frac{\sum_{k=1}^{m} \sum_{l=1}^{m} c_{k l}}{m(m-1)} \\
=\frac{\sum_{k=1}^{10} \sum_{l=1}^{10} c_{k l}}{10(10-1)}=6.522
\end{gathered}
$$

The matrix element $f_{k l}$ is determined by Eq. 5. So the concordance dominant matrix can be seen in Table VI.

$$
f_{k l}=\left\{\begin{array}{l}
1, \text { jika } c_{k l} \geq \underline{c} \\
0, \text { jika } c_{k l}<\underline{c}
\end{array}\right.
$$

b) Calculates the dominant matrix of discordance. The threshold value $(\underline{d})$ is Eq. 6 .

$$
\begin{aligned}
& \underline{d}=\frac{\sum_{k=1}^{m} \sum_{l=1}^{m} d_{k l}}{m(m-1)} \\
& =\frac{\sum_{k=1}^{10} \sum_{l=1}^{10} d_{k l}}{10(10-1)}=0,63
\end{aligned}
$$

The matrix element $g_{k l}$ is determined by Eq. 7. So the dominant matrix of discordance can be seen in Table VII.

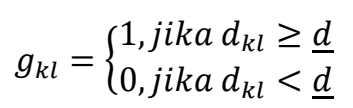

6) Determine the dominant matrix of aggregate. The general formula for calculating the dominant matrix of aggregates using Eq. 8. So the result of dominant aggregate matrix can be seen in Table VIII.

$$
e_{k l}=f_{k l} \times g_{k l}
$$

7) Alternative elimination. Matrix E gives the order of choice of each alternative, the best alternative is Raja Banana with a value of 4 . This result is the same as the result shown by the application system that has been created. Thus based on the results of manual and program calculations, it can be 
concluded that theoretically the best alternative bananas that can be planted on trial land in the Samarinda is a plantain. The best alternative selection result made by the system can be seen in Fig. 2.

TABLE VIII. AGGREGATE DOMINANT MATRIX

\begin{tabular}{|l|l|l|l|l|l|l|l|l|l|l|}
\hline & 1 & 2 & 3 & 4 & 5 & 6 & 7 & 8 & 9 & 10 \\
\hline 1 & - & 0 & 0 & 1 & 1 & 0 & 0 & 0 & 1 & 0 \\
\hline 2 & 0 & - & 0 & 0 & 0 & 0 & 0 & 0 & 1 & 0 \\
\hline 3 & 1 & 1 & - & 0 & 0 & 0 & 0 & 0 & 1 & 0 \\
\hline 4 & 1 & 0 & 0 & - & 0 & 1 & 0 & 0 & 1 & 0 \\
\hline 5 & 0 & 0 & 0 & 0 & - & 0 & 0 & 0 & 0 & 0 \\
\hline 6 & 1 & 0 & 0 & 1 & 1 & - & 0 & 0 & 1 & 0 \\
\hline 7 & 0 & 0 & 0 & 0 & 1 & 0 & - & 1 & 1 & 0 \\
\hline 8 & 0 & 0 & 0 & 0 & 1 & 0 & 0 & - & 0 & 0 \\
\hline 9 & 0 & 0 & 0 & 0 & 0 & 0 & 0 & 0 & - & 0 \\
\hline 10 & 0 & 1 & 1 & 0 & 0 & 0 & 0 & 0 & 1 & - \\
\hline
\end{tabular}

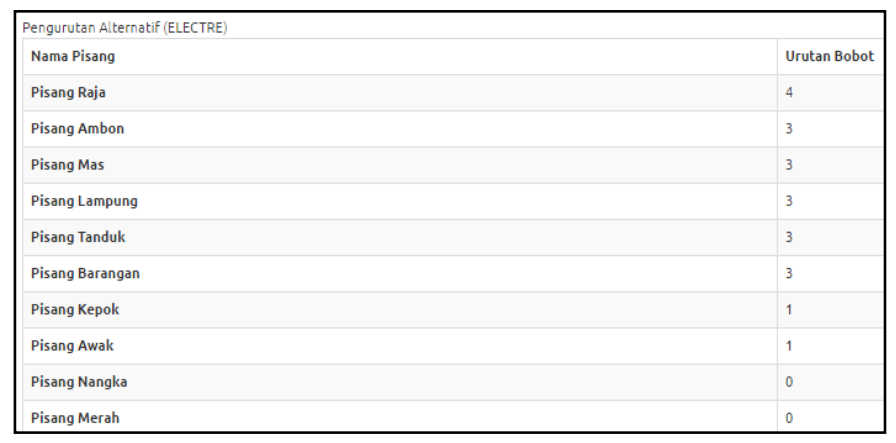

Fig. 2. The Best Alternative Selection with the ELECTRE Method

\section{CONCLUSIONS}

The ELECTRE method has been successfully applied in the selection of decision support systems of banana varieties in Samarinda area. The criteria chosen in this research were soil type, rainfall, soil fertility, and soil $\mathrm{pH}$ can be processed and then produce recommendation through stages that have been specified in ELECTRE method. The best result of banana varieties of the system is Raja Banana with a value of 4, followed by Ambon Banana, Mas Banana, Lampung Banana, Tanduk Banana, and Barangan Banana with a value of 3.

\section{ACKNOWLEDGMENT}

Data of Banana Varieties and Land Criteria used are data from Ir. Akhyar Roeslan, MP and has been verified by Devis Hendra, SP, MP., as a Head of Plantation Development of Horticulture Agriculture Agency of East Kalimantan.

\section{REFERENCES}

[1] F. Agus, R. Sholeh, H. R. Hatta, and T. Munawwarah, "Fuzzy Analytical Hierarchy Process for Land Suitability Analysis Compared to Analytical Hierarchy Process," in 1st International Conference on Information Technology, Computer, and Electrical Engineering: Green Technology and Its Applications for a Better Future, ICITACEE 2014, Semarang, 2014, pp. 129-132.

[2] F. Agus, Sumaryono, S. Lambang, and R. Afif, "Document Individual decision model for urban regional land planning," in 1st International Conference on Information Technology, Computer, and Electrical Engineering: Green Technology and Its Applications for a Better Future, ICITACEE 2014, Semarang, Indonesia, 2014, pp. 260-265.

[3] Hamdani, A. Septiarini, and D. M. Khairina, "Model assessment of land suitability decision making for oil palm plantation," in 2nd International Conference on Science in Information Technology, ICSITech 2016: Information Science for Green Society and Environment, Balikpapan, Indonesia, 2016, pp. 109-113.

[4] D. P. ISMI, S. PANCHOO, and M. MURINTO, "K-means clustering based filter feature selection on high dimensional data," International Journal of Advances in Intelligent Informatics, vol. 2, n. 1, mar. 2016, pp. 38-45, 2016.

[5] A. Holzinger, "Biomedical Decision Making: Reasoning and Decision Support," in TU Graz: Medical Informatics vol. 444 (152), ed, 2011, pp. $1-55$.

[6] J. P. Holdren and E. S. Lander, "Big Data and Privacy: A Technological Perspective," The President's Council of Advisors on Science and Technology (PCAST), Washington, DC, USA2014.

[7] S. Rahman, H. Odeyinka, S. Perera, and Y. Bi, "Product-cost modelling approach for the development of a decision support system for optimal roofing material selection," Expert Systems with Applications, vol. 39, pp. 6857-687, 2012.

[8] A. Ishizaka and H. N. Nguyen, "Calibrated fuzzy AHP for current bank account selection," Expert Systems with Applications, vol. 40, pp. 37753783, 2013.

[9] G. Buyokozkan and G. Cifci, "A novel hybrid MCDM approach based on fuzzy DEMATEL, fuzzy ANP and AHP-TOPSIS to evaluate green suppliers," Expert Systems with Applications, vol. 39, pp. 3000-3011, 2012

[10] Purnawansyah and Haviluddin, "K-Means Clustering Implementation in Network Traffic Activities," in 2016 International Conference on Computational Intelligence and Cybernetics, Makassar, Indonesia, 2016, pp. 51-54. 